\title{
Rectangular reinforced concrete tank loaded by seismic load
}

\author{
Lenka Uhlířová ${ }^{1, *}$ and Norbert Jendželovský ${ }^{2}$ \\ ${ }^{1}$ Faculty of Civil Engineering STU in Bratislava, Radlinského 11, 81005 Bratislava, Slovakia \\ ${ }^{2}$ Faculty of Civil Engineering STU in Bratislava, Radlinského 11, 81005 Bratislava, Slovakia
}

\begin{abstract}
Tanks have currently been used for storage of different substances and products. Most often they serve as reservoirs for drinking water, for wastewater treatment and storage of various technical liquids. Rectangular tanks are less common, still there are many benefits of their using, e.g. lower sensitivity to unilateral load and better use of space mainly in systems of multiple tanks.

The rectangular tank analyzed in this article is filled with water. Our investigation is focused on dynamic analysis of the tank. The tank was loaded by accelerogram of a natural earthquake. Step-by-step method was used for the calculation. The model was created using ANSYS Academic software, which is based on the Finite Element Method (FEM). The particular calculation was performed using the transient analysis. A time course of displacements and accelerations of each point of a structure has been obtained. The state of stress in walls during the period of maximum displacements has been presented.
\end{abstract}

\section{Introduction}

Three numerical methods (Finite Element Method, Finite Strips Method and Boundary Elements Method) have been used to analyze the problems of continuum mechanics. Thanks to advances in the computer software, the Finite Element Method (FEM) became the most frequently used one. It is based on variational principles. For calculations presented in this article, ANSYS Academic software had been used.

In the example presented in this paper, a rectangular tank filled with water has been modeled (more about the model can be found in Chapter 2). A first step of a dynamic analysis is the determination of eigenshapes and eigenfrequencies of an analyzed structure. A modal analysis had been used for this purpose, out of its results the first six eigenshapes have been presented in this paper (see Chapter 3).

Next, a calculation of effects caused by a dynamic load of a tank was performed. The method of direct integration (the step-by-step method) had been used. We focus on obtained results of the displacement of the tank loaded by natural earthquake.

\footnotetext{
*Corresponding author: lenka.uhlirova@ stuba.sk
} 


\subsection{Step-by-step method}

Theoretical background of this method has been described in [1]. The method is based on a procedure in which behaviour of the system in the end of a particular time step is derived from the conditions valid at the beginning of the same step. As a matter of fact, it is a method of a direct integration in time, whose solution has been made gradually in time steps, and that's why, when using this method, the nonlinear response of a structure can be considered. The time step is very small (hundredths and thousandths of a second), here we have to define the change of acceleration in the given time step (constant or linear behaviour). By integration of acceleration we obtain the acceleration function. By integration of the acceleration function we obtain the displacement function.

\section{The model of a tank}

The tank analyzed in this paper is a rectangular, above-ground, reinforced concrete tank, fixed in the foundations. Its dimensions are $11 \mathrm{~m} \mathrm{x} \mathrm{7,5} \mathrm{m} \mathrm{and} \mathrm{its} \mathrm{height} \mathrm{is} \mathrm{4,5} \mathrm{m.} \mathrm{The} \mathrm{tank}$ is filled with water whose level reaches $4 \mathrm{~m}$, to avoid the unwanted splashing out when the tank is under effects of a dynamic load. The model of the tank is presented in Fig. 1.

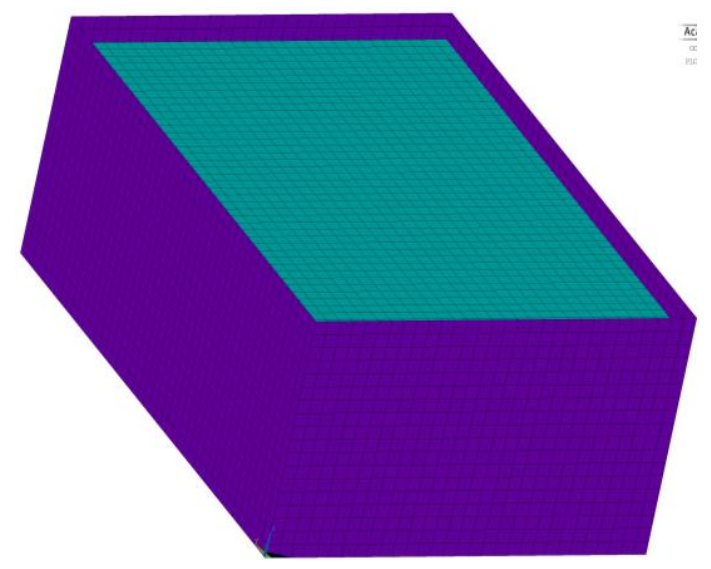

Fig. 1. The model of a tank.

For static modeling of the tank walls $200 \mathrm{~mm}$ thick and the tank bottom $500 \mathrm{~mm}$ thick in the ANSYS software the quadrilateral planar element SHELL181 had been used (Fig. 2). For modeling of the tank filling - water, the fluid 3D element FLUID80 had been used (Fig. 3.).
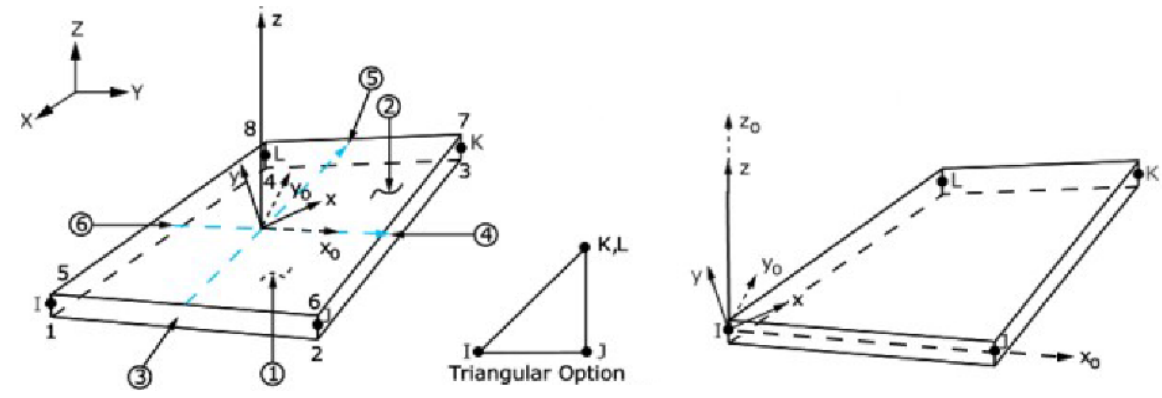

Fig. 2. Element SHELL181 [2]. 


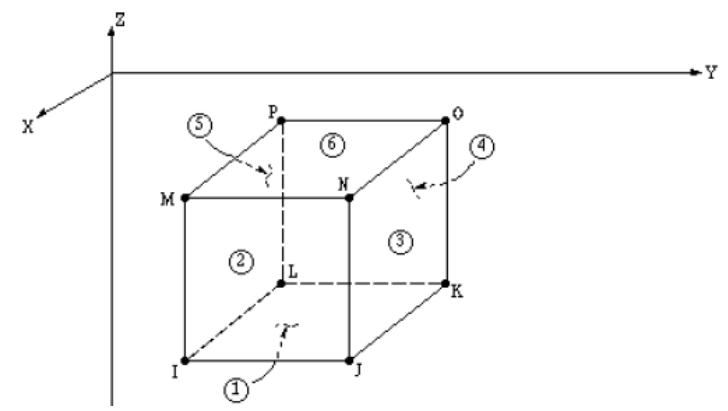

Fig. 3. Element FLUID80 [2].

Dynamic analysis of tanks has been described in detail in articles [3-6]. The earthqake accelerogram presented in Fig. 4 provided the input values for the dynamic calculation. Overall time of the eartquake effects is $10 \mathrm{~s}$, while the time step is $0,01 \mathrm{~s}$. (For the sake of clarity of the graph, the first 5 seconds of record are shown.)

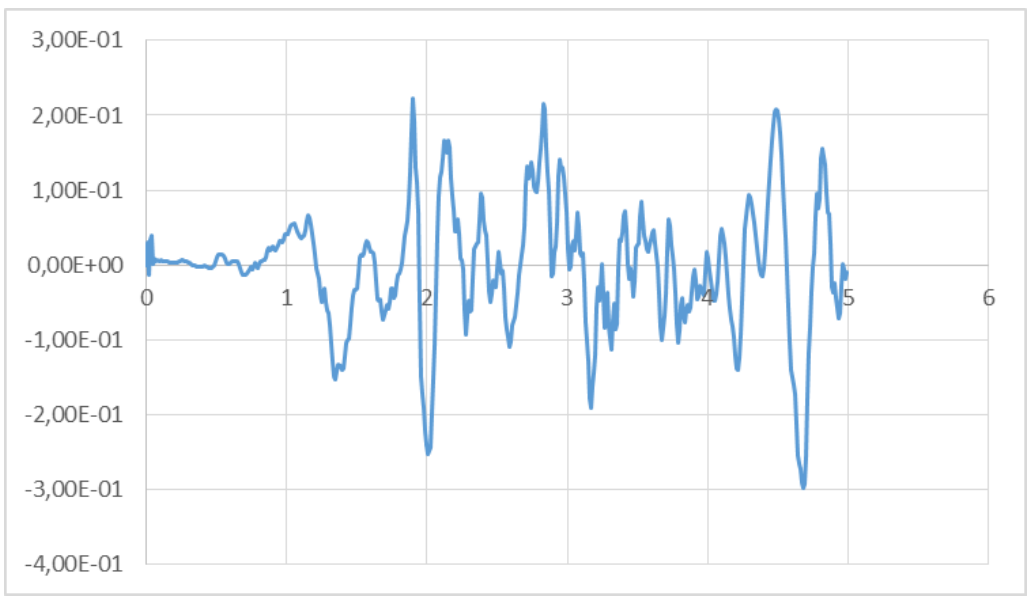

Fig. 4. Accelerogram of the analyzed earthquake.

\section{Results of the modal analysis}

Prior to analysis of the earthquake using the step-by-step method, the modal analysis of a structure had been performed. From the modal analysis of the example described in the previous Chapter the eigenshapes, their frequencies and values of the participation factor $\gamma$ had been obtained. It was necessary to separate eigenshapes, at which only the level of water is in motion, from the eigenshapes at which the overall tank structure is oscillating. Out of these selected eigenshapes, first two eigenshapes have been presented in Fig. 5 and in Fig. 6. First six eigenshapes together with values of frequencies and participation factor $\gamma$ have been presented in Table 1 . 


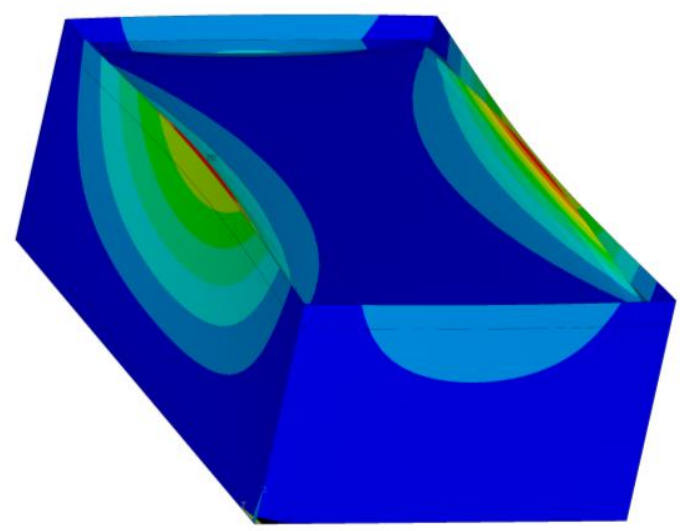

Fig. 5. Eigenshape No. $1(\mathrm{f}=5,758 \mathrm{~Hz})$.

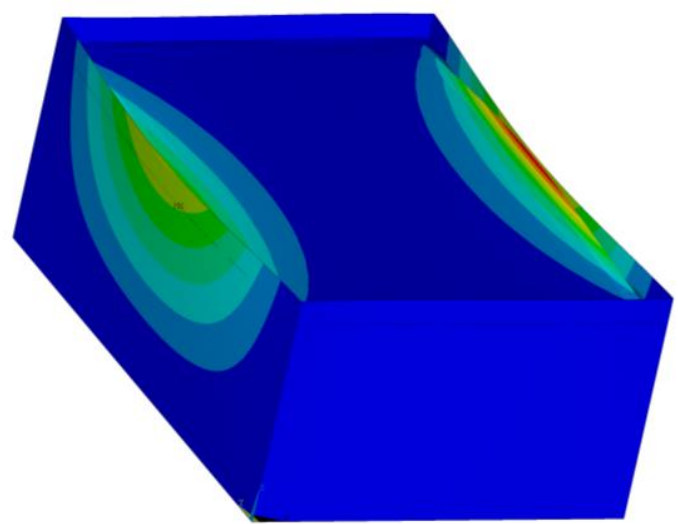

Fig. 6. Eigenshape No. 2 ( $\mathrm{f}=6,051 \mathrm{~Hz})$.

Table 1. Values of frequencies and the participation factor of individual eigenshapes of the rectangular tank.

\begin{tabular}{|c||c|c|c|}
\hline Eigenshape No. & Frequency f & Participation factor $\gamma$ & Direction of $\gamma$ \\
\hline \hline 1 & $5,758 \mathrm{~Hz}$ & 4,308 & $\mathrm{Z}$ \\
\hline 2 & $6,051 \mathrm{~Hz}$ & $-10,835$ & $\mathrm{X}$ \\
\hline 3 & $8,476 \mathrm{~Hz}$ & 8,647 & $\mathrm{Y}$ \\
\hline 4 & $8,792 \mathrm{~Hz}$ & 5,567 & $\mathrm{Z}$ \\
\hline 5 & $11,793 \mathrm{~Hz}$ & 28,066 & - \\
\hline 6 & $12,099 \mathrm{~Hz}$ & $-4,634$ & $\mathrm{Y}$ \\
\hline
\end{tabular}

\section{Results of the step-by-step method}

After loading of a structure by an accelerogram of a given earthquake, the results had been obtained using the step-by-step method. Out of a large amount of obtained results, we present the graph of horizontal displacement of a point in time where the maximal values of displacement had been achieved. Virtually it is a point in the middle of an upper edge of the longer wall. The mentioned course of the horizontal displacement of a point is presented in Fig. 7. 


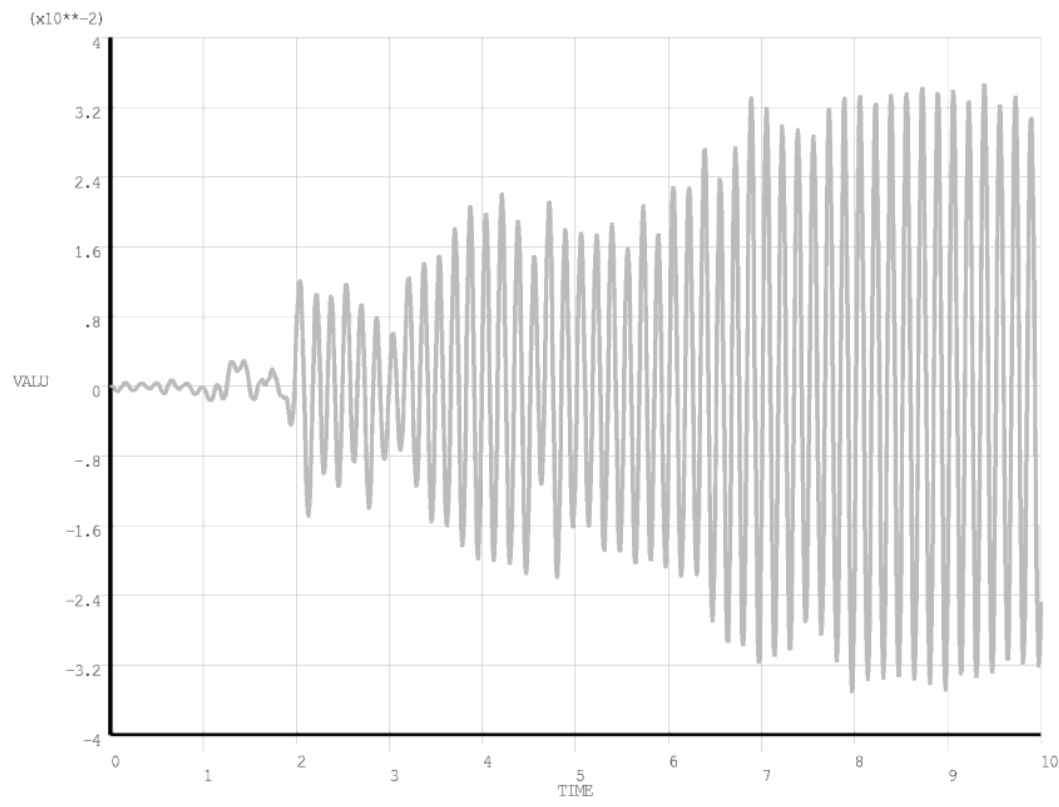

Fig. 7. Displacement of a node in time (in the $\mathrm{x}$ axis direction) in the middle of a longer wall due to the seismic loading in $\mathrm{m}$.

Subsequently, exact time was determined, in which the displacement of a point achieved its maximal value. This has occurred in time 7,97 s, and we present the displacements of a tank in the $x$ axis direction (Fig. 8) and in the $y$ axis direction (Fig. 9) achieved in this time. In the Figure Caption the maximum value of the tank walls displacement has been mentioned. Water in this time achieved largest displacements in the $\mathrm{z}$ axis direction, with the value $162,8 \mathrm{~mm}$. The still water level is $500 \mathrm{~mm}$ lower than the edge of tank walls, so there is no risk of splashing the water out of tank.

As displacement values of the water are different from those of the tank walls, some distortion of the scale of displacement plotting occurred. Thus for plotting of Figures, only the tank structure was selected.

Specific bending moments in the tank walls mx (Fig. 10) and my (Fig. 11) have been plotted on the structure.

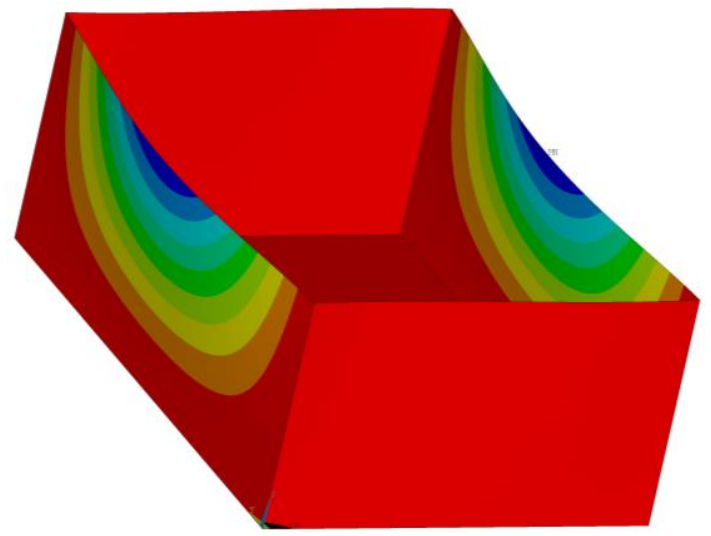

Fig. 8. Displacement in the $\mathrm{x}$ axis direction in time 7,97 $\mathrm{s}\left(\mathrm{u}_{\mathrm{x}}=35,186 \mathrm{~mm}\right)$ due to the seismic loading. 


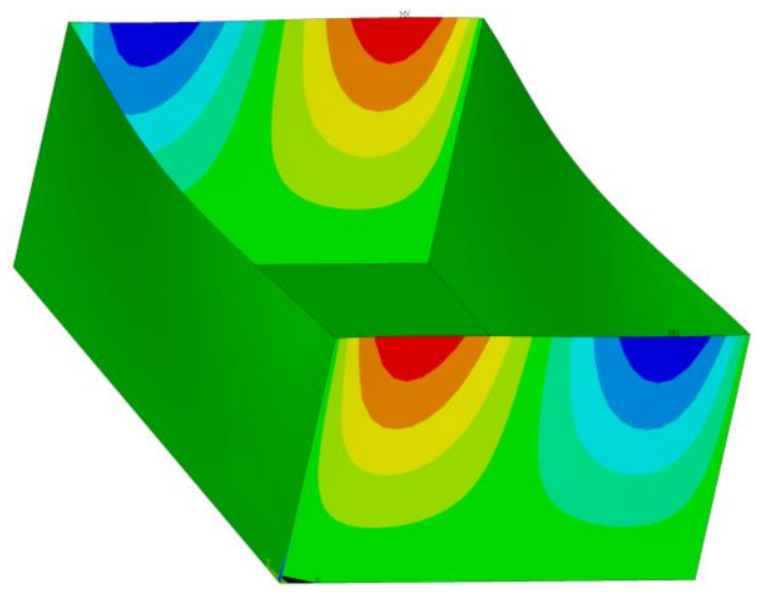

Fig. 9. Displacement in the y axis direction in time 7,97 s $\left(\mathrm{u}_{\mathrm{y}}=3,162 \mathrm{~mm}\right)$ due to the seismic loading.

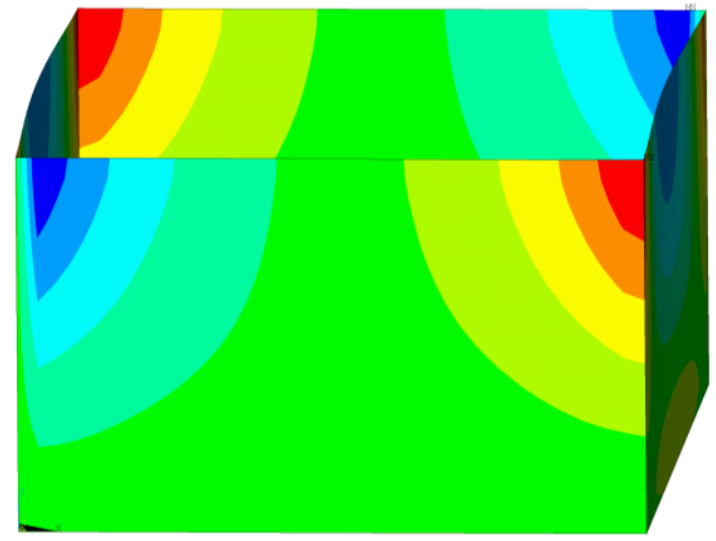

Fig. 10. Specific moment $m_{x}$ in tank walls in time $7,97 \mathrm{~s}(\max .=101,847 \mathrm{kNm} / \mathrm{m})$.

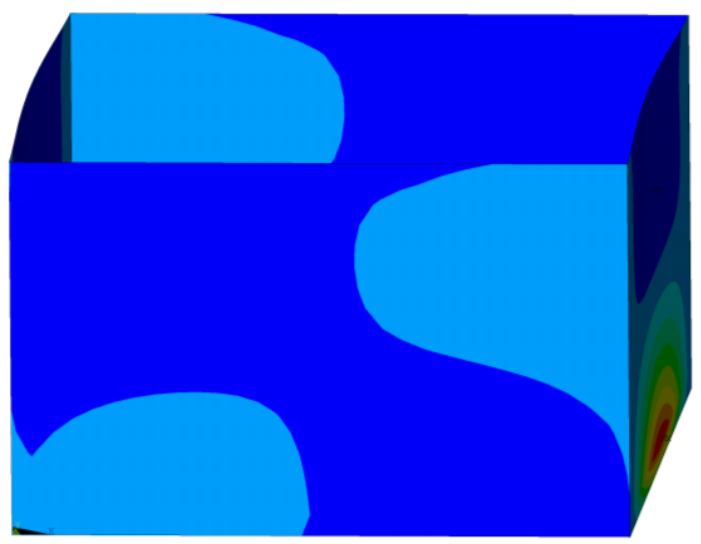

Fig. 11. Specific moment $\mathrm{m}_{\mathrm{y}}$ in tank walls in time $7,97 \mathrm{~s}(\max .=188,319 \mathrm{kNm} / \mathrm{m})$. 
This paper was supported by Grant Agency VEGA, project No. 1/0412/18.

This paper was supported of Student Grant STU Young Researcher 1686.

\section{References}

1. Sokol, M. - Tvrdá, K. Dynamika stavebných konštrukcií (Bratislava: STU v Bratislave 2011), ISBN 978-80-227-3587-2

2. ANSYS Help, Theory Reference for the Mechanical APDL and Mechanical Applications

3. Kotrasová, K. - Kormaníková, E.: International Journal of Mechanics (2016), 10, 242252

4. Kotrasová, K. - Leoveanu, I. S. - Kormaníková, E.: Buletinul AGIR (2013), Vol. 18, no. 3, 120-125.

5. Kotrasová, K. - Kormaníková, E., 9th International Conference on Material in Engineering Practice (2014); 113119.

6. Kala, J. - Salajka, V. - Hradil, P.: ICETI 2012: 2nd International Conference on Engineering and Technology Innovation, 2-6 November, 2012, Taiwan, 1269-1272. 